\title{
Formation of Polycyclic Aromatic Hydrocarbons (PAHs) in Lamb during Roasting
}

(Received May 17, 1993)

\author{
Masuo Nakano and Michihiro Fukushima \\ (Department of Bioresource Chemistry, Obihiro University of Agriculture and \\ Veterinary Medicine: Inada-cho, Obihiro, Hokkaido 080, Japan)
}

\begin{abstract}
Formation of polycyclic aromatic hydrocarbons (PAHs) in lamb grilled over charcoal and changes of PAH content with roasting time are described. Two hundred grams of lamb meat containing $65.2 \%$ moisture was grilled over charcoal for $0,3,5,10,15$ and 20 min at $500 \sim$ $600^{\circ} \mathrm{C}$. The roasted meat was homogenized with $600 \mathrm{ml}$ of chloroform-methanol $(2: 1, \mathrm{v} / \mathrm{v})$ and extracted three times. After filtration and clean-up on a silica gel column and by thin-layer chromatography, PAHs were analyzed by high performance liquid chromatography and gas liquid chromatography-mass spectrometry. The lipid content decreased with increasing heating time. The maximum concentrations of PAHs were $49.0 \mathrm{ppb}$ for pyrene, $40.9 \mathrm{ppb}$ for chrysene, $36.0 \mathrm{ppb}$ for fluoranthene, $28.0 \mathrm{ppb}$ for 9 -methylanthracene, $17.1 \mathrm{ppb}$ for anthracene, and $8.9 \mathrm{ppb}$ for phenanthrene at $3 \mathrm{~min}$ roasting, and $17.4 \mathrm{ppb}$ for benzo[a]pyrene at $5 \mathrm{~min}$ roasting. The mutagenic activity of each $\mathrm{PAH}$ decreased with increasing heating time. PAH formation was well correlated with lipid contents in lamb meat $(r=0.926, p<0.05)$.
\end{abstract}

Key words: polycyclic aromatic hydrocarbons; charcoal; lamb meat; high performance liquid chromatography (HPLC); gas liquid chromatography-mass spectrometry (GC/MS); mutagenic activity

\section{Introduction}

Polycyclic aromatic hydrocarbons (PAHs) are known to be widespread in the environment. They are present in smoke from burning plants and exhaust gas from diesel engines, and are formed during the combustion and carbonization of many fossil fuels. ${ }^{1) \sim 3)}$ Similarly, carbohydrates, proteins and lipids of organic materials produce PAHs during combustion at high temperature. It is accordingly possible that PAHs are distributed not only in the atmosphere, aquatic sphere and soil but also in cooked foods, such as mutton, chicken, fish and vegetables. ${ }^{4) \sim 7)}$ It has been reported that nitro-PAHs exist in smoked foods, such as smoked chicken. ${ }^{8)}$ These reports suggested that many PAHs are produced by cooking. However, the formation of PAHs during cooking on charcoal fires has not been reported so far. Charcoal grilling of lamb meat is a widespread cooking habit, in Hokkaido particularly.

This paper describes the composition of PAHs found in lamb meat grilled over charcoal, and the changes of PAH content with roasting time.

\section{Materials and Methods}

\section{Materials}

All organic solvents were used after distillation. Anthracene, chrysene, benzo $[a]$ pyrene $(\mathrm{B}[a] \mathrm{P})$ and dibenzo $[a, h]$ anthracene were obtained from Tokyo Kasei Industries Co.; phenanthrene, pyrene and 9-methylanthracene from Wako Pure Chem. Industries; fluoranthene from Eastman Kodak Co.; and silicic acid (100 mesh AR) from Mallinckrodt Co. Lamb meat was obtained from a commercial source.

\section{Extraction and clean-up of $P A H$}

Two hundred grams of lamb meat containing $65.2 \%$ moisture was directly grilled over charcoal for $0,3,5,10,15$ and $20 \mathrm{~min}$ at $500 \sim 600^{\circ} \mathrm{C}$. The temperature was measured at the charcoal surface using a Yamato solid-state power controller connected to a thermo-detector and was confirmed to remain in the range of 500 to $600^{\circ} \mathrm{C}$ 
during roasting. Extraction and clean-up of $\mathrm{PAH}$ were carried out according to the method of Negishi et al. $^{8)}$ The roasted lamb was homogenized in $600 \mathrm{ml}$ of chloroform-methanol $(2: 1$, $\mathrm{v} / \mathrm{v})$ and extracted three times. The extracts were combined and concentrated on a rotary evaporator in vacuo to obtain the lipid. One gram of the lipid was taken up in cyclohexane and subjected to silica gel ( $30 \mathrm{~g}$ ) column chromatography. The PAHs were eluted successively with $200 \mathrm{ml}$ of cyclohexane, $200 \mathrm{ml}$ of cyclohexane-benzene ( $1: 1, \mathrm{v} / \mathrm{v}), 200 \mathrm{ml}$ of benzene, $200 \mathrm{ml}$ of chloroform-methanol $95: 5$, v/ v), $200 \mathrm{ml}$ of chloroform-methanol $(9: 1, \mathrm{v} / \mathrm{v})$ and $200 \mathrm{ml}$ of chloroform-methanol $(2: 1, \mathrm{v} / \mathrm{v})$. Allfractions were subjected to thin-layer chromatography (TLC) using Merck precoated silica gel 60 plates and cyclohexane-chloroform $(1: 1$, $\mathrm{v} / \mathrm{v})$ as a solvent system. The spots in the cyclohexane-benzene $(1: 1, \mathrm{v} / \mathrm{v})$ fraction corresponding to the reference PAH standard were scraped off and the compounds absorbed on silica gel were eluted with chloroform-methanol $(2: 1, \mathrm{v} / \mathrm{v})$ using a sonicator $(45 \mathrm{kHz})$. The eluate was filtered.

\section{Analysis of $P A H$}

A Hitachi Model 638 high performance liquid chromatograph (HPLC) fitted with an ERC-ODS1171 column $(6.0 \times 200 \mathrm{~mm})$ was used. The composition of the mobile phase was acetonitrilewater $(7: 3, \mathrm{v} / \mathrm{v})$ and the effluent was monitored at $254 \mathrm{~nm}$. The flow rate was $1.0 \mathrm{ml} / \mathrm{min}$ at 150 $\mathrm{kg} / \mathrm{cm}^{2}$ and the column oven temperature was

Table 1. Recovery of PAHs Added to Lamb Meat

\begin{tabular}{lc}
\hline \multicolumn{1}{c}{ Added PAH } & $\begin{array}{c}\text { Average } \\
\text { recovery (\%) } \\
\text { (two runs) }\end{array}$ \\
\hline Anthracene+ phenanthrene & 84.5 \\
Fluoranthene & 95.0 \\
Pyrene & 87.6 \\
Chrysene & 88.0 \\
Benzo $[a]$ pyrene & 85.0 \\
Dibenzo $[a, h]$ anthracene & 84.9 \\
\hline
\end{tabular}

The peak corresponding to anthracene+ phenanthrene in GC/MS was calculated with respect to total contents of added anthracene and phenanthrene standards. $30^{\circ} \mathrm{C}$.

Gas liquid chromatography-mass spectrometry (EI, GC/MS) was performed on a Shimadzu QP-1000 using a capillary fused silica column $(0.33 \mathrm{~mm} \times 25 \mathrm{~m})$ coated with CBP-1. Operating conditions were as follows: injection temperature, $300^{\circ} \mathrm{C}$; column temperature, $180 \sim 270^{\circ} \mathrm{C}$ at $5^{\circ} \mathrm{C} / \mathrm{min}$; flow rate of the carrier gas (helium), 30 $\mathrm{ml} / \mathrm{min}$; ion source and molecular separator temperature, $250^{\circ} \mathrm{C}$ and ionization voltage, 70 $\mathrm{eV}$.

\section{Recovery test of PAH}

Recovery tests of anthracene, phenanthrene, fluoranthene, pyrene, chrysene, $\mathrm{B}[a] \mathrm{P}$ and di benzo[a,h] anthracene added at levels of $100 \mu \mathrm{g}$, respectively, to $100 \mathrm{~g}$ of lamb meat were done by $\mathrm{GC} / \mathrm{MS}$.

\section{Statistical analysis}

The statistical significance of differences between values was analyzed by using the Pearson correlation coefficient.

Table 2. Yields of Lipids from Roasted Lamb

\begin{tabular}{cccc}
\hline $\begin{array}{c}\text { Roasting } \\
\text { time } \\
(\mathrm{min})\end{array}$ & $\begin{array}{c}\text { Lamb } \\
\text { weight } \\
(\mathrm{g})\end{array}$ & $\begin{array}{c}\text { Yield } \\
(\mathrm{g})\end{array}$ & $\begin{array}{c}\text { Content } \\
(\%)\end{array}$ \\
\hline 0 & 200.0 & 37.97 & 18.99 \\
3 & 200.0 & 28.91 & 14.46 \\
5 & 200.0 & 21.71 & 10.86 \\
10 & 200.0 & 10.14 & 5.07 \\
15 & 200.0 & 5.00 & 2.50 \\
20 & 200.0 & 2.20 & 1.10 \\
\hline
\end{tabular}

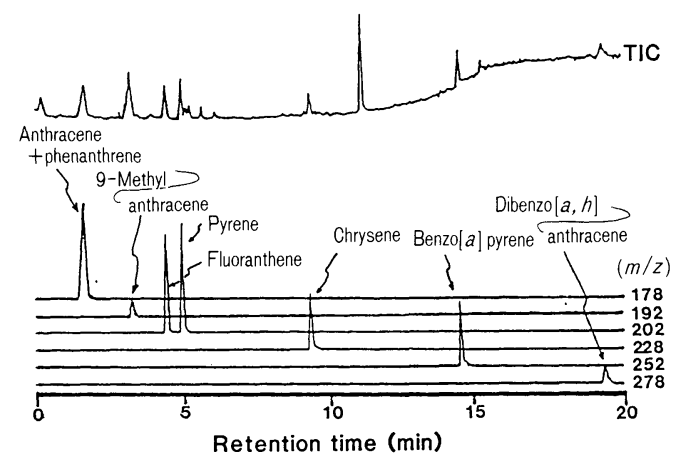

Fig. 1. TIC and mass chromatograms of polycyclic aromatic hydrocarbons in roasted lamb 


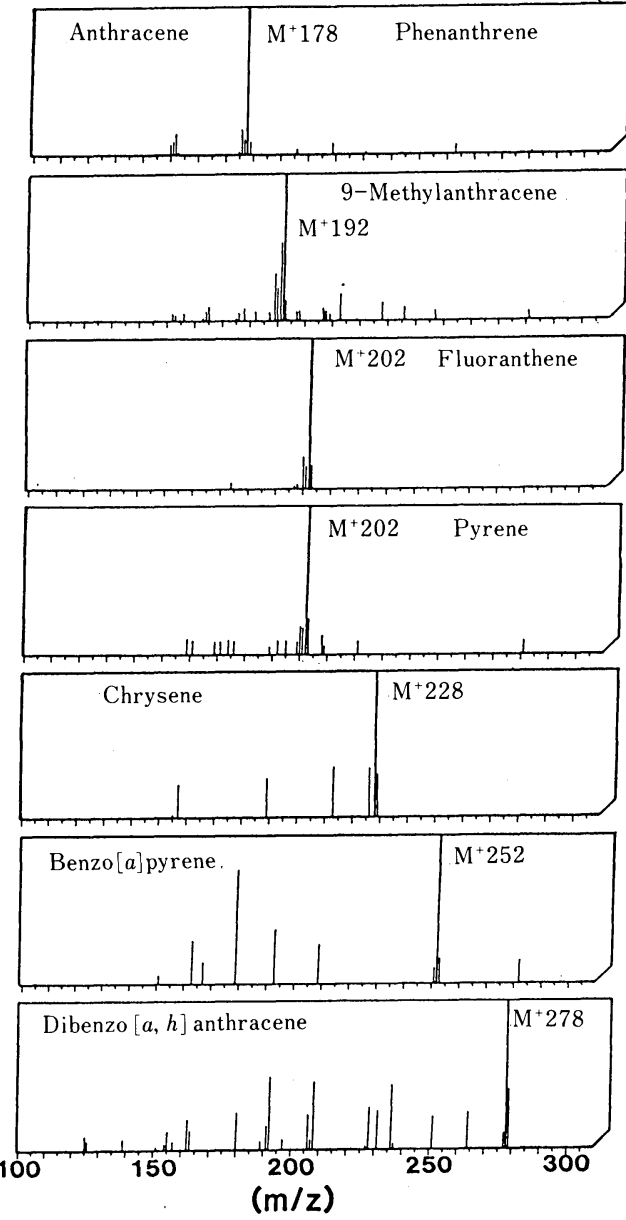

Fig. 2. Mass spectra of polycyclic aromatic hydrocarbons in roasted lamb

\section{Results and Discussion}

The recoveries of PAHs added to lamb meat are shown in Table 1 . The recoveries were in the range of $84.5 \sim 95.0 \%$ and are quite sufficient for the present purpose. The lipids in the chloroform-methanol $(2: 1, \mathrm{v} / \mathrm{v})$ extract from each roasted lamb sample are shown in Table 2 . The amounts decreased with increasing grilling time and the content ranged from 1.1 to $19.0 \%$. This decrease was considered to reflect the loss of fat by dripping onto the heat source. The amounts in the eluate from the silica gel column chromatography with cyclohexane-benzene $(1: 1, \mathrm{v} /$ v) ranged from 154.4 to $3807.3 \mathrm{mg}$ for 3 and 20 min, respectively and also decreased with increasing heating time.

PAHs in the eluates were purified by TLC and were identified as anthracene, phenanthrene, 9 methylanthracene, pyrene, chrysene, $\mathrm{B}[a] \mathrm{P}$ and dibenzo $[a, h]$ anthracene by GC/MS (Figs. 1 and 2). PAHs were quantified by GC/MS and HPLC. Anthracene and phenanthrene, which were not separated by GC/MS, were separated by HPLC

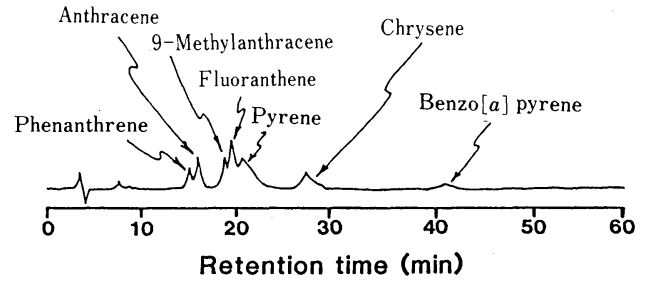

Fig. 3. HPLC chromatogram of polycyclic aromatic hydrocarbons in roasted lamb

Table 3. Contents of Polycyclic Aromatic Hydrocarbons (PAHs) in Roasted Lamb

\begin{tabular}{lrrrrrr}
\hline \hline \multirow{2}{*}{ PAH component } & \multicolumn{7}{c}{ Roasting time (min) } \\
\cline { 2 - 7 } & 0 & 3 & 5 & 10 & 15 & 20 \\
\hline & 0.7 & 17.1 & 14.9 & 16.5 & 5.2 & 9.5 \\
Anthracene & 0.4 & 8.9 & 7.8 & 8.6 & 2.7 & 5.0 \\
Phenanthrene & ND & 28.0 & 14.4 & 12.3 & 0.7 & ND \\
9-Methylanthracene & ND & 36.4 & 23.9 & 32.7 & 4.1 & 2.1 \\
Fluoranthene & ND & 49.0 & 21.2 & 30.2 & 3.9 & 2.0 \\
Pyrene & ND & 40.9 & 23.9 & 10.2 & 0.5 & 7.6 \\
Chrysene & ND & 16.9 & 17.4 & 6.6 & 0.9 & 6.7 \\
Benzo $[a]$ pyrene & ND & ND & ND & ND & ND & 5.8 \\
Dibenzo $[a, h]$ anthracene & NDy
\end{tabular}

ND: not detectable (0.1 ppb)

Anthracene and phenanthrene were quantified by HPLC and other PAHs were quantified by GC/MS. 


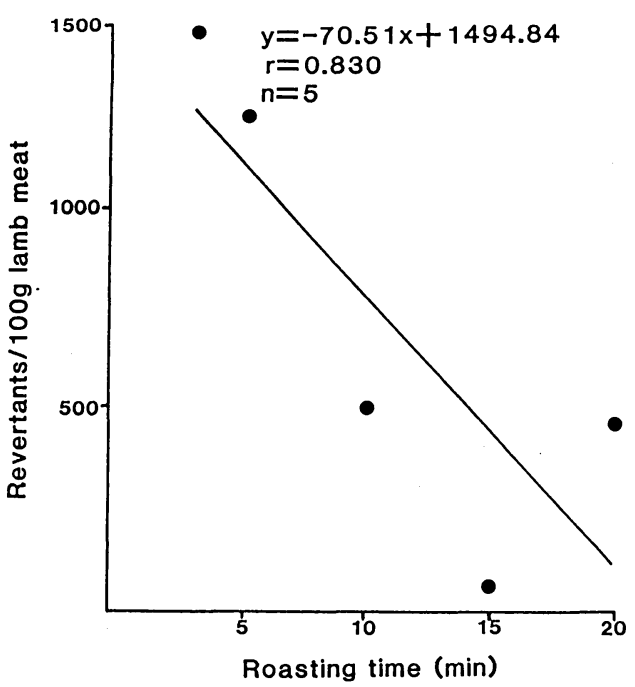

Fig. 4. Relation between mutagenic activity of polycyclic aromatic hydrocarbons on TA 100 and roasting time

Points were calculated from chrysene $1670 / 10$, benzo[a]pyrene $2398 / 5$ and dibenzo $[a, h]$ anthracene $401 / 10$ revertants per plate $(\mu \mathrm{g})$, with Salmonella typhimurium TA100 strain

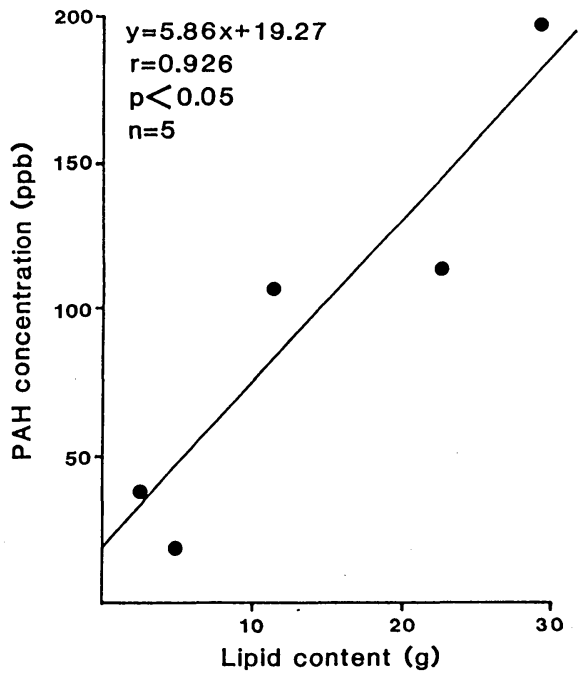

Fig. 5. Relation between lipid content and total polycyclic aromatic hydrocarbons concentration in roasted lamb

(Fig. 3).

The content of each PAH induced by roasting is shown in Table 3. The maximum concentrations of PAH were $49.0 \mathrm{ppb}$ for pyrene, $40.9 \mathrm{ppb}$ for chrysene, $36.0 \mathrm{ppb}$ for fluoranthene, $28.0 \mathrm{ppb}$ for 9-methylanthracene, $17.1 \mathrm{ppb}$ for anthracene, and $8.9 \mathrm{ppb}$ for phenanthrene at $3 \mathrm{~min}$ roasting, and $17.4 \mathrm{ppb}$ for $\mathrm{B}[a] \mathrm{P}$ at 5 min roasting. Dibenzo $[a, h]$ anthracene $(5.8 \mathrm{ppb})$ was detected only at $20 \mathrm{~min}$. These results conflict with a report that the maximum concentrations of $\mathrm{B}[a] \mathrm{P}$ and chrysene were detected after 25 min. ${ }^{7}$ The difference may be caused by the cooking methods and the cooking temperatures. In fact, PAH levels in lamb meat and the influence of cooking time upon $\mathrm{PAH}$ formation were similar to those in sardines, presumably since these samples were grilled directly. ${ }^{6}$ ) It is general that the formation of PAHs is accelerated at $500 \sim 800^{\circ} \mathrm{C}^{9)}$ Although the lamb meat was grilled at the cooking temperature of 500 $600^{\circ} \mathrm{C}$ in this experiment, Sivaswamy et al. fried mutton meat on a pan at a cooking temperature of $220 \sim 225^{\circ} \mathrm{C}$.

The relation between mutagenic activity of PAHs and the roasting time is shown in Fig. 4; Salmonella typhimurium TA 100 strain was used. ${ }^{10)}$ It was reported that the mutagenicity was increased by longer heating. ${ }^{11)}$ However, in this experiment, it was suggested that the mutagenic activity of $\mathrm{PAH}$ was highest at $3 \mathrm{~min}$, when the lamb was sufficiently roasted for eating, and decreased after grilling for $5 \mathrm{~min}$. The correlation coefficient $(r)$ between the mutagenic activity and the roasting time was 0.830 . It may be considered that the formation rate of PAHs was accelerated, but the PAHs were lost in fat that dripped onto the heat source, since the cooking temperature was higher than that in other reports. ${ }^{6), 7), 11)}$

$\mathrm{PAH}$ concentration in relation to the lipid content is shown in Fig. 5. The PAH concentration correlated positively with the lipid content, the correlation coefficient $(r)$ being $0.926(p<0.05)$. This is consistent with the relation between lipid content and amount of 3,4-benzopyrene in fish. ${ }^{4)}$ It is considered that PAHs are produced from cholesterol, triacylglycerol, fatty acid and carotenoid, ${ }^{4), 12)}$ but in this experiment we did not investigate the composition of lipid in the roasted lamb meat. The relation between the lipid composition and the formation of PAHs by charcoal grilling is now being examined.

It was concluded that PAH concentration in roasted lamb was highest at $3 \mathrm{~min}$ in this exper- 
iment, when the lamb meat was sufficiently roasted for eating. The barbecue style using charcoal is popular in Hokkaido. It will be necessary to investigate the formation of PAHs in barbecued materials other than lamb meat.

\section{References}

1) Thomas, D. B., Ronald, A. H.: Environ. Sci. Technol. 18, 202 206 (1984).

2) Thomas, R., Georg, B.: Analytica Chimica Acta 144, 83 91 (1982).

3) Grimmer, G., Jacob, J., Dettbarn, G., Naujack, K. W.: Anal. Chem. 322, 595 602 (1985).

4) Yamazaki, H., Minami, J., Ichikawa, T., Kondo, M.: J. Food Hyg. Soc. Japan 18, 368 374 (1977).

5) Tateno, T., Nagumo, Y., Suenaga, S.: ibid. 31, 271 $\sim 276$ (1990).

6) Saint-Aubert, B., Cooper, J. F., Astre, C., Spiliotis,
J., Joyeux, H.: J. Food Compos. Anal. 5, 257 263 (1992).

7) Sivaswamy, S. N., Nagarajan, B.: Med. Sci. Res. 19, 289 290 (1991).

8) Negishi, T., Nakano, M., Yanai, K., Kim, C. H., Fukushima, M.: Environ. Pollut. 50, 279 283 (1988).

9) Committee on Biologic Effects of Atmospheric Pollutants ed.: "Particulate Polycyclic Organic Matter" p. 12 32 (1981), Tokyo Kagaku Doujin, Tokyo.

10) Matsuoka, H.: Kagaku no Ryoiki 129, 115 134 (1980).

11) Waller, G. R., Feather, M. S. ed.: "The Maillard Reaction in Foods and Nutrition" p. 485 506 (1983), American Chemical Society, Washington, D. C.

12) Halaley, G. A., Fagerson, I. S.: Int. Congr. Food Sci. Technol. 3, 820 829 (1970). 